\title{
Prevalence of hepatitis B virus marker positivity and evolution of hepatitis B virus profile, during chemotherapy, in patients with solid tumours
}

\author{
CG Alexopoulos ${ }^{1}$, M Vaslamatzis ${ }^{1}$ and G Hatzidimitriou² \\ 'Department of Medical Oncology and ²Blood Transfusion Unit, Evangelismos Hospital, 45 Ipsilantou Str, Athens 106 76, Greece
}

\begin{abstract}
Summary To prospectively evaluate the prevalence of hepatitis B virus (HBV) positivity and study the evolution of HBV profile during cancer chemotherapy, serum HBV markers and liver biochemistry were determined in 1008 of 1402 (72\%) cancer patients admitted in our Unit and in all $920(91 \%)$ who received chemotherapy. We found that $54(5.3 \%)$ were HBsAg carriers while $443(44 \%)$ had at least one HBV marker positive. Of the latter, 405 (91\%) were HBcAb+ve, 321 (72\%) HBsAb+ve and 212 (48\%) HBeAb+ve. No patient was HBeAg+ve. Among 920 chemotherapy receivers, 374 (41\%) were HBcAb+ve, $280(30 \%)$ HBsAb+ve and $178(19 \%)$ HBeAb+ve. Fifty (5.4\%) were HBsAg carriers (versus $0.6 \%$ in Greek blood donors). All 50 were systematically screened for HBsAg and HBsAb status throughout chemotherapy, during follow-up or until their death, and liver biochemistry was performed before each chemotherapy course. Stable antigenaemia was observed in $43 / 50(86 \%)$ while $7 / 50(14 \%)$ developed clinical and/or biochemical hepatitis. Six of these seven developed serum anti-HBs antibodies with an associated decrease of serum HBsAg titres. We conclude that reactivation of HBV infection during chemotherapy is not rare (14\%), while disappearance of HBs antigenaemia is neither a frequent nor usually a permanent phenomenon.
\end{abstract}

Keywords: HBsAg carriers; HBV profile; cancer chemotherapy

Reactivation of hepatitis B virus (HBV) infection in patients with haematologic malignancies receiving cytotoxic or immunosuppressive therapy is well documented (Wands et al, 1975; Lau et al, 1989; Pinto et al, 1990; Ohtsu et al, 1991). It is of interest that in some of those HBsAg carriers who developed hepatitis during cytotoxic treatment, seroconversion to an HBsAg-negative state was observed (Scullard et al, 1981; Hoofnagle et al, 1982; Alexopoulos et al, 1992).

Information of this kind, in HBsAg-positive patients with solid tumours, treated with cytotoxic chemotherapy, is very limited and consisted mainly of case reports (Gallbraith et al, 1975; Ohtsu et al, 1991; Pinto et al, 1990; Alexopoulos et al, 1992). We therefore decided to undertake a systematic prospective study of the HBV profile in such patients, with a twofold aim:

1. to evaluate the prevalence of HBV marker positivity in patients with solid tumours

2. to study the evolution of HBV profile and the behaviour of HBsAg carrier state during anti-neoplastic chemotherapy.

Our findings have been previously presented, in abstract form, in the 33nd Annual Meeting of the American Society of Clinical Oncology (Alexopoulos et al, 1997).

\section{PATIENTS AND METHODS}

\section{Prevalence of HBV markers positivity}

\section{Patient population}

Between 1986 and 1995, 1402 patients with various solid tumours were admitted to the Department of Medical Oncology at

Received 22 July 1998

Revised 15 January 1999

Accepted 12 April 1999

Correspondence to: CG Alexopoulos
Evangelismos Hospital. In 1008 of them (72\%) serum markers for HBV infection were determined before any anticancer chemotherapy was given (Group A).

A total of 920 patients $(91 \%)$ of Group A received antineoplastic chemotherapy (Group B) and they served as the main focus in studying the prevalence of marker positivity. The decision for not giving chemotherapy in the remaining 88 patients was based solely on the absence of reasonably effective chemotherapy for their tumour, their performance status and the presence of specific medical contra-indications. No patient was excluded on the basis of the liver status.

\section{Methods}

Serum markers for $\mathrm{HBV}$ infection, including $\mathrm{HBsAg}, \mathrm{HBeAg}$, $\mathrm{HBsAb}, \mathrm{HBcAb}$, and $\mathrm{HBeAb}$, were determined using specific third-generation enzyme-linked immunosorbent assay (ELISA; Abbott), at the time of initial presentation in all patients (Group A) and it was repeated before chemotherapy in the 920 patients of Group B. Positive results were repeated for confirmation. Liver function tests including SGOT, SGPT, $\gamma$ GT, LDH, alkaline phosphatase, bilirubin, phrothrombin time and serum proteins were also performed at the same time as HBV profile, before the administration of any treatment.

\section{Evaluation of HBV profile and behaviour of $\mathrm{HBsAg}$ carrier state during anti-neoplastic chemotherapy}

\section{Patient population}

Among the 920 patients who received chemotherapy, 538 (59\%) patients had HBV markers determined before and after the completion of their chemotherapy (Group C), while in 391 (43\%) patients HBV markers were serially determined before chemotherapy, just after chemotherapy and during their follow-up 
(Group D). These two groups of patients served as the focus in studying the evolution of $\mathrm{HBV}$ profile during antineoplastic chemotherapy.

There were $50 \mathrm{HBsAg}$ carriers among the 920 patients of Group $\mathrm{B}$ and all of them were systematically screened for HBsAg and HBsAb status throughout chemotherapy, during their follow-up or until their death. Finally, in 30 of the $50(60 \%)$ HBsAg carriers, we had the opportunity to monitor their HBV profile before, in the middle, just after the completion of chemotherapy and repeatedly during their follow-up. Both these groups served as the focus in studying the behaviour of HBsAg carrier status during cancer chemotherapy.

\section{Methods}

Clinical and laboratory monitoring was as follows:

- History was taken and clinical examination was performed before each course of chemotherapy, during treatment and every 2 months during follow-up.

- $\quad$ Serum HBV marker determined before, in the middle, just after the completion of chemotherapy and during the follow-up every 2 months, for 1 year.

- Liver function tests including SGOT, SGPT, rGT, LDH, alkaline phosphatase, bilirubin, prothrombin time and serum proteins were performed before each course of chemotherapy during treatment, and every 2 months during follow-up, for 1 year.

\section{Statistics}

Chi-square test was used for comparison of findings.

\section{RESULTS}

\section{Patients characteristics}

Among the 1008 patients tested before any treatment was given (Group A), 460 (45.6\%) were men and 548 (54.4\%) women with a median age of 59 years (17-78) compared with $426(46.3 \%)$ men and $494(53.6 \%)$ women with a median age of 58 years (19-78), in the 920 patients who subsequently received anticancer chemotherapy (Group B). The distribution of the various malignant solid tumours in the two groups (A and B) together with the prevalence of $\mathrm{Hbs} \mathrm{Ag}$ carriers in each type of malignant tumour are shown in Tables 1 and 2.

\section{Prevalence of HBV marker positivity}

The prevalence of HBV markers in each of the four groups (A, B, C and D) is shown in Table 3. In Group A, a total of 443 patients (44\%) had at least one marker positive, indicating previous exposure to HBV infection. Fifty-four patients $(5.3 \%)$ were found to be HBsAg carriers, and 321 patients (32\%) were HBsAb-positive. No patient was found to be $\mathrm{HBeAg}$-positive, while 212 (21\%) were $\mathrm{HBeAb}$-positive. Finally, 405 patients (40\%) had HBc antibodies in their sera, representing $91 \%$ of those screened positive for at least one marker. None of the 443 patients with at least one HBV marker positive was demonstrating clinical or biochemical evidence of hepatitis (data not shown).

The pre-chemotherapy prevalence of HBV marker positivity in Group B was not statistically different from that of Group A (Table 3). More specifically, the prevalence of HBsAg carriers was $5.4 \%$,
Table 1 Distribution of the various types of cancer and prevalence of $\mathrm{HBsAg}$ carrier state in the 1008 patients, screened before any anticancer treatment was given (Group A)

\begin{tabular}{lrcrc}
\hline Type of cancer & $\begin{array}{c}\text { Men } \\
(\%)\end{array}$ & $\begin{array}{c}\text { Women } \\
(\%)\end{array}$ & $\begin{array}{c}\text { Total } \\
\text { (\%) }\end{array}$ & $\begin{array}{c}\text { Hbs Ag +ve } \\
(\%)\end{array}$ \\
\hline Carcinoma of the lung & 196 & 35 & 231 & $15(6.5)$ \\
Carcinoma of the breast & 1 & 260 & 261 & $8(3)$ \\
Carcinoma of the Gl tract $^{\mathrm{a}}$ & 103 & 67 & 170 & $7(4.1)$ \\
HD and NHL & 55 & 58 & 113 & $14(12.4)$ \\
Urothelial cancer & 59 & 27 & 86 & $4(4.7)$ \\
Head and neck cancer & 10 & 6 & 16 & $2(12.5)$ \\
Cancer of the ovary & - & 85 & 85 & $4(4.7)$ \\
Other cancers & 35 & 11 & 46 & 0 \\
Total & $460(45.6)$ & $548(54.4)$ & 1008 & $54(5.36)$ \\
& & & &
\end{tabular}

${ }^{a}$ Excluding hepatocellular carcinoma.

Table 2 Distribution of the various types of cancer and prevalence of $\mathrm{HbsAg}$ carrier state in the 920 patients who received anticancer chemotherapy (Group B)

\begin{tabular}{|c|c|c|c|c|}
\hline Type of cancer & $\begin{array}{c}\text { Men } \\
(\%)\end{array}$ & $\begin{array}{c}\text { Women } \\
(\%)\end{array}$ & Total & $\begin{array}{c}\text { HbsAg +ve } \\
(\%)\end{array}$ \\
\hline Carcinoma of the lung & 176 & 25 & 201 & $14(6.9)$ \\
\hline Carcinoma of the breast & 1 & 225 & 226 & $6(2.65)$ \\
\hline Carcinoma of the Gl tract ${ }^{\mathrm{a}}$ & 90 & 59 & 149 & $6(4)$ \\
\hline $\mathrm{HD}$ and $\mathrm{NHL}$ & 55 & 58 & 113 & $14(12.4)$ \\
\hline Urothelial cancer & 59 & 27 & 86 & $4(4.7)$ \\
\hline Head and neck cancer & 10 & 4 & 14 & $2(14.3)$ \\
\hline Cancer of the ovary & - & 85 & 85 & $4(4.7)$ \\
\hline Other cancers & 35 & 11 & 46 & 0 \\
\hline Total & $426(46.4)$ & $494(53.6)$ & 920 & $50(5.4)$ \\
\hline
\end{tabular}

${ }^{a}$ Excluding hepatocellular carcinoma.

and a total of 396 patients $(43 \%)$ had at least one HBV marker positive. Of them, 94\% were HBcAb-positive. Similarly, prechemotherapy findings concerning the prevalence of $\mathrm{HBsAg}$ carrier state, $\mathrm{HBcAb}$ positivity and the presence of at least one HBV marker positive were not significantly different in Groups C and D (Table 3). On the contrary, comparison between the four groups demonstrated a significantly $(P<0.001)$ lower prevalence of serum anti-HBe antibodies in Groups $\mathrm{C}$ and D and of anti-HBs antibodies in Group D (Table 3).

\section{Evolution of HBV profile and HBsAg carrier behaviour during anti-neoplastic chemotherapy}

Table 4 summarizes the findings concerning the changes of HBV profile just after chemotherapy in the 538 patients of Group C. For each HBV marker, the overall seroconversion rate was calculated by dividing the absolute number of changes observed in the corresponding marker with the total number of patients screened (Table 4). Among $37 \mathrm{HBsAg}$ carriers, one had lost HBs antigenaemia after six courses of chemotherapy while no change was observed in the status of $501 \mathrm{HBsAg}$-negative patients for an overall seroconversion rate of $0.2 \%$ for $\mathrm{HBsAg}$ marker. On the other hand, among $151 \mathrm{HBsAb}$-positive patients, five lost their HBs antibodies after six courses of chemotherapy, while 15 of the remaining $387 \mathrm{HBsAb}$-negative patients developed HBs antibodies in their sera. This represents a $3.7 \%$ seroconversion rate for $\mathrm{HBs} \mathrm{Ab}$ marker. The corresponding overall seroconversion rates, 
Table 3 Prevalence of HBV markers in 1008 patients tested at presentation (Group A), 920 patients who received chemotherapy (Group B), 538 patients tested before and after chemotherapy (Group C) and 391 patients with serial marker determination before and after chemotherapy and during follow-up (Group D). Results of comparisons between the four groups, for each HBV marker, are shown below with asterisks

\begin{tabular}{|c|c|c|c|c|c|c|c|}
\hline $\begin{array}{l}\text { Patient } \\
\text { population }\end{array}$ & Patient no. & $\begin{array}{c}\text { HBs Ag+ } \\
(\%)\end{array}$ & $\begin{array}{c}\text { Hbe Ag+ } \\
(\%)\end{array}$ & $\begin{array}{c}\text { HBs Ab+ } \\
(\%)\end{array}$ & $\begin{array}{c}\text { Hbe Ab+ } \\
\text { (\%) }\end{array}$ & $\begin{array}{c}\text { HBc Ab+ } \\
(\%)\end{array}$ & $\begin{array}{c}\text { Any +ve } \\
(\%)\end{array}$ \\
\hline Group A & 1008 & $54(5.3)$ & 0 & 321 (32) & $212(21)$ & $405(40)$ & $443(44)$ \\
\hline Group B & 920 & $50(5.4)^{\mathrm{a}}$ & 0 & $280(30)^{a}$ & $178(19)^{\mathrm{a}}$ & $374(41)^{a}$ & $396(43)^{a}$ \\
\hline Group C & 538 & $37(6.9)^{\mathrm{a}}$ & 0 & $151(28)^{a}$ & $80(15)^{b}$ & $195(36)^{a}$ & $215(40)^{a}$ \\
\hline Group D & 391 & $30(7.7)^{\mathrm{a}}$ & 0 & $86(22)^{b}$ & $50(13)^{b}$ & $150(40)^{a}$ & $157(40)^{a}$ \\
\hline
\end{tabular}

aStatistically non-significant; 'bstatistically significant.

Table 4 Changes in HBV profile in 538 patients screened before and just after chemotherapy (Group C)

\begin{tabular}{|c|c|c|c|c|}
\hline HBV marker & Before chemo & After chemo & $\begin{array}{c}\text { Absolute number } \\
\text { of changes } \\
(\%)\end{array}$ & $\begin{array}{c}\text { Overall } \\
\text { seroconversion rate }\end{array}$ \\
\hline HBsAg-ve & 501 & 501 & 0 & \\
\hline HBsAb +ve & 151 & 146 & 5 & $20(3.7)$ \\
\hline $\mathrm{HBeAg}$-ve & 538 & 538 & 0 & \\
\hline $\mathrm{HBeAb}+\mathrm{ve}$ & 80 & 77 & 3 & $13(2.4)$ \\
\hline $\mathrm{HBeAb}-\mathrm{ve}$ & 458 & 448 & 10 & \\
\hline $\mathrm{HBcAb}+\mathrm{ve}$ & 195 & 195 & 0 & $25(4.6)$ \\
\hline $\mathrm{HBcAb}-\mathrm{ve}$ & 343 & 318 & 25 & \\
\hline
\end{tabular}

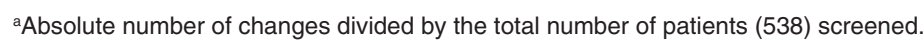

Table 5 Evolution of HBV profile in 391 patients serially tested before, just after chemotherapy, and during their follow-up (Group D)

\begin{tabular}{lcccc}
\hline HBV marker & Before chemotherapy & After chemotherapy & $\begin{array}{c}\text { During follow-up } \\
\text { Overall change }\end{array}$ \\
\hline $\mathrm{HBsAg}+\mathrm{ve}$ & 30 & 30 & 6.6 \\
$\mathrm{HBsAb}+\mathrm{ve}$ & 86 & 83 & 4.7 & 28 \\
$\mathrm{HBeAg}+\mathrm{ve}$ & 0 & 0 & 82 & 0 \\
$\mathrm{HBeAb}+\mathrm{ve}$ & 50 & 53 & 58 & 170 \\
$\mathrm{HBcAb}+\mathrm{ve}$ & 150 & 159 & 13.3 \\
\hline
\end{tabular}

for $\mathrm{HBeAb}$ and $\mathrm{HBcAb}$ markers, were $2.4 \%$ and $4.6 \%$ respectively. No change whatsoever was observed in relation to $\mathrm{HBeAg}$ status.

The evolution of HBV profile, in 391 patients in whom HBV markers were serially determined before, just after chemotherapy and during follow-up (Group D), is presented in Table 5. Two of 30 HBsAg-positive patients became HBsAg-negative during followup, for an overall change of $6.6 \%$. Among $86 \mathrm{HBsAb}$-positive patients, three lost their HBs antibodies after six courses of chemotherapy and another one during follow-up, for an overall change of $4.7 \%$. Major changes were also observed in $\mathrm{HBeAb}$ and $\mathrm{HBcAb}$ status. Thus, while before chemotherapy 50 patients screened positive for $\mathrm{HBeAb}$, the corresponding numbers were 53 after six courses and 58 during follow-up for an overall change of $16 \%$. Likewise, nine patients developed $\mathrm{HBc}$ antibodies after six courses of chemotherapy and another 11 during follow-up, for an overall change of $13.3 \%$ (Table 5). Finally, serum HBV antigenaemia remained unchanged in 43 of $50(86 \%)$ HBsAg carriers, in all measurements performed, and none of these patients developed clinical signs of hepatitis or liver function abnormalities. Nevertheless, in seven of $50(14 \%)$, a considerable increase in serum hepatocellular enzymes was observed, during chemotherapy, with or without clinical signs of hepatitis. Information about the clinical course, chemotherapeutic regimens and the use of corticosteroids in these seven cases is given in Table 6, while Table 7 summarizes the changes in the serum HbsAg and HbsAb titres together with liver function abnormalities observed during anticancer chemotherapy. Six of seven $(86 \%)$ patients developed anti-HBs antibodies in their sera with a parallel decrease in the titre of HbsAg (a more detailed presentation concerning these seven patients is planned soon).

In 30 of the $50(60 \%)$ HBsAg carriers, monitoring of HBV profile before, in the middle, just after the completion of chemotherapy and repeatedly during follow-up gave the results shown in Table 8. Two of the $30 \mathrm{HBsAg}$-positive patients (6.6\%) seroconverted to a $\mathrm{HBsAg}$-negative status during their follow-up. Among 28 HBsAb-negative patients, three (11\%) developed HBs antibodies. None of the $30 \mathrm{HBcAb}$-positive patients lost serum 
Table 6 Clinical course, type of chemotherapy used and use of prednisone in the seven patients who developed HBV reactivation as a result of antineoplastic chemotherapy

\begin{tabular}{|c|c|c|c|c|c|c|}
\hline $\begin{array}{l}\text { Patient } \\
\text { no. }\end{array}$ & Sex/Age & Diagnosis $^{a}$ & $\begin{array}{l}\text { Chemotherapeutic regimen } \\
\text { (time of HBV reactivation) }\end{array}$ & Prednisone & Outcome & $\begin{array}{l}\text { Resumption of } \\
\text { chemotherapy }\end{array}$ \\
\hline 1 & $\mathrm{M} / 48$ & $\mathrm{NHL}$ & $\begin{array}{l}\text { CTX+VCR+ADRIA+PRD } \\
\text { (3rd course of chemo) }\end{array}$ & No & $\begin{array}{l}\text { Complete } \\
\text { recovery }\end{array}$ & $\begin{array}{l}\text { Yes } \\
\text { ( } 3 \text { courses })\end{array}$ \\
\hline 2 & $\mathrm{M} / 77$ & SCLC & $\begin{array}{l}\mathrm{CTX}+\mathrm{MTX}+\mathrm{VCR}+\mathrm{VP}-16 \\
\text { (6th course of chemo) }\end{array}$ & Yes & $\begin{array}{l}\text { Complete } \\
\text { recovery }\end{array}$ & No \\
\hline 3 & $\mathrm{M} / 48$ & SCLC & $\begin{array}{l}\mathrm{CTX}+\mathrm{MTX}+\mathrm{VCR}+\mathrm{ADRIA}+\mathrm{VP}-16 \\
\text { (4th course of chemo) }\end{array}$ & No & $\begin{array}{l}\text { Complete } \\
\text { recovery }\end{array}$ & No \\
\hline 4 & $F / 63$ & $\mathrm{NHL}$ & $\begin{array}{l}\text { CTX+VCR+ADRIA+PRD } \\
\text { ( } 2 \text { nd course of chemo) }\end{array}$ & Yes & $\begin{array}{l}\text { Complete } \\
\text { recovery }\end{array}$ & $\begin{array}{l}\text { Yes } \\
\text { (4 courses) }\end{array}$ \\
\hline 5 & $\mathrm{M} / 53$ & $\mathrm{NHL}$ & $\begin{array}{l}\text { IFO+VP-16 } \\
\text { (4th course of chemo) }\end{array}$ & No & $\begin{array}{l}\text { Complete } \\
\text { recovery }\end{array}$ & $\begin{array}{l}\text { Yes } \\
(2 \text { courses) }\end{array}$ \\
\hline 6 & $\mathrm{M} / 67$ & APUD & $\begin{array}{l}\text { 5-FU+FA } \\
\text { (6th course of chemo) }\end{array}$ & No & $\begin{array}{l}\text { Complete } \\
\text { recovery }\end{array}$ & No \\
\hline 7 & $\mathrm{M} / 62$ & $\mathrm{NHL}$ & $\begin{array}{l}\text { CTX+VCR+ADRIA+PRD } \\
\text { (3rd course of chemo) }\end{array}$ & Yes & $\begin{array}{l}\text { Complete } \\
\text { recovery }\end{array}$ & $\begin{array}{l}\text { Yes } \\
\text { (3 courses) }\end{array}$ \\
\hline
\end{tabular}

$\mathrm{NHL}=$ Non Hodgkin's lymphoma; SCLC = small-cell lung cancer; APUD = neuroendocrine tumour; CTX = cyclophosphamide; VCR = vincristine; ADRIA = adriamycin; PRD = prednisone; $M T X=$ methotrexate; VP-16 = vepesid IFO = ifosfamide; 5 -FU = fluorouracil; FA = folinic acid.

Table 7 Changes in HBs antigenaemia, titre of serum HBsAb, and liver function tests in the seven HBsAg carriers who developed clinical and/or biochemical evidence of hepatitis during anticancer chemotherapy

\begin{tabular}{|c|c|c|c|c|c|c|c|c|c|}
\hline Patient no. & $\begin{array}{l}\text { Timing } \\
\text { Re: chemo }\end{array}$ & HbsAg & HBsAb & SGOT & SGPT & $\gamma \mathbf{G T}$ & Bilirubin & LDH & PT \\
\hline \multirow[t]{3}{*}{1} & Before & 3500 & $-v e$ & 25 & 25 & 10 & 0.4 & 232 & $11^{\prime \prime} / 11^{\prime \prime}$ \\
\hline & Middle & 2200 & 750 & 340 & 550 & 27 & 0.8 & 491 & $11^{\prime \prime} / 13^{\prime \prime}$ \\
\hline & After & 1500 & 900 & 25 & 28 & 12 & 0.5 & 277 & $11^{\prime \prime} / 11^{\prime \prime}$ \\
\hline \multirow[t]{4}{*}{2} & Before & 4000 & -ve & 20 & 20 & 9 & 0.8 & 320 & $11^{\prime \prime} / 11^{\prime \prime}$ \\
\hline & Middle & 4600 & $-v e$ & 25 & 28 & 19 & 0.6 & 270 & $11^{\prime \prime} / 11^{\prime \prime}$ \\
\hline & After & 2600 & 800 & 700 & 500 & 117 & 17 & 1925 & $12^{\prime \prime} / 21^{\prime \prime}$ \\
\hline & Follow-up & $-v e$ & 1300 & 20 & 15 & 23 & 0.4 & 212 & $11^{\prime \prime} / 12^{\prime \prime}$ \\
\hline \multirow[t]{3}{*}{3} & Before & 4000 & $-v e$ & 20 & 20 & 10 & 0.65 & 219 & $11^{\prime \prime} / 12^{\prime \prime}$ \\
\hline & Middle & 2800 & 900 & 1900 & 1300 & 56 & 12.5 & 629 & $12^{\prime \prime} / 20^{\prime \prime}$ \\
\hline & After & 2500 & 1000 & 20 & 20 & 19 & 1.25 & 323 & $11^{\prime \prime} / 12^{\prime \prime}$ \\
\hline \multirow[t]{3}{*}{4} & Before & 3000 & $-v e$ & 39 & 25 & 12 & 0.7 & 361 & $11^{\prime \prime} / 11^{\prime \prime}$ \\
\hline & Middle & 1600 & 700 & 388 & 315 & 27 & 4.1 & 384 & $11^{\prime \prime} / 16^{\prime \prime}$ \\
\hline & After & 900 & 800 & 28 & 13 & 11 & 0.5 & 170 & $11^{\prime \prime} / 12^{\prime \prime}$ \\
\hline \multirow[t]{4}{*}{5} & Before & 2500 & -ve & 20 & 17 & 9 & 0.7 & 150 & $12^{\prime \prime} / 11^{\prime \prime}$ \\
\hline & Middle & 1000 & $-v e$ & 25 & 20 & 10 & 0.8 & 162 & $11^{\prime \prime} / 11^{\prime \prime}$ \\
\hline & After & -ve & 1500 & 140 & 190 & 36 & 2.4 & 468 & $11^{\prime \prime} / 17^{\prime \prime}$ \\
\hline & Follow-up & $-v e$ & 1800 & 18 & 13 & 5 & 1.3 & 170 & $12^{\prime \prime} / 12^{\prime \prime}$ \\
\hline \multirow[t]{4}{*}{6} & Before & 1800 & $-v e$ & 26 & 18 & 7.7 & 0.6 & 232 & $13^{\prime \prime} / 12^{\prime \prime}$ \\
\hline & Middle & 1100 & $-v e$ & 22 & 20 & 11 & 0.5 & 228 & $12^{\prime \prime} / 12^{\prime \prime}$ \\
\hline & After & -ve & 1000 & 120 & 115 & 57 & 0.7 & 259 & $13^{\prime \prime} / 11^{\prime \prime}$ \\
\hline & Follow-up & $-v e$ & 1300 & 20 & 15 & 18 & 0.65 & 241 & $12^{\prime \prime} / 11^{\prime \prime}$ \\
\hline \multirow[t]{4}{*}{7} & Before & 3100 & $-v e$ & 22 & 17 & 8 & 0.9 & 207 & $12^{\prime \prime} / 11^{\prime \prime}$ \\
\hline & Middle & 3000 & $-v e$ & 24 & 21 & 12 & 0.75 & 205 & $11^{\prime \prime} / 11^{\prime \prime}$ \\
\hline & After & 1600 & $-v e$ & 124 & 129 & 10 & 0.85 & 220 & $11^{\prime \prime} / 12^{\prime \prime}$ \\
\hline & Follow-up & 1500 & $-v e$ & 14 & 16 & 12 & 0.7 & 196 & $11^{\prime \prime} / 11^{\prime \prime}$ \\
\hline
\end{tabular}

Table 8 Monitoring of HBV profile throughout chemotherapy and during follow-up in $30 \mathrm{HBsAg}$ carrier patients

\begin{tabular}{|c|c|c|c|c|c|}
\hline HBV marker & Before & Middle & After & Follow-up & $\begin{array}{c}\text { Overall change } \\
(\%)\end{array}$ \\
\hline HBsAg +ve & 30 & 29 & 28 & 28 & $-2(6.6)$ \\
\hline HBsAb +ve & 2 & 3 & 2 & 5 & +3 (67) \\
\hline HBsAb -ve & 28 & 27 & 28 & 25 & $-3(11)$ \\
\hline $\mathrm{HBcAb}+\mathrm{ve}$ & 30 & 29 & 28 & 30 & None \\
\hline $\mathrm{HBcAb}$-ve & 0 & 1 & 2 & 0 & NA \\
\hline $\mathrm{HBeAb}+\mathrm{ve}$ & 29 & 29 & 29 & 30 & $+1(3.5)$ \\
\hline $\mathrm{HBeAb}-\mathrm{ve}$ & 1 & 1 & 1 & 0 & $-1(100)$ \\
\hline
\end{tabular}


anti-HBc antibodies as a result of anti-neoplastic chemotherapy, while the only $\mathrm{HBcAb}$-negative patient developed serum anti-HBc antibodies during follow-up.

\section{DISCussion}

Reactivation of HBV infection leading to clinically evident hepatitis as a result of the administration of antineoplastic chemotherapy, in HBsAg carriers, has been well known from several case reports (Bird et al, 1989; Pinto et al, 1990; Ohtsu et al, 1991; Alexopoulos et al, 1992; Nakamura et al, 1996). Wands et al (1975) surveyed 85 patients with myeloproliferative and lymphoproliferative diseases who were given antineoplastic chemotherapy and observed that, after chemotherapy, HBsAg titres often increased.

Interestingly enough, a systematic evaluation of the incidence of HBV marker positivity, in a large number of untreated patients with solid tumours and a prospective study of the changes of HBV profile, during antineoplastic chemotherapy, has not been published so far. From this point of view, our findings referring to 1008 of $1402(72 \%)$ patients with various solid tumours admitted to the Department of Medical Oncology at Evangelismos Hospital, and to all 920 patients among them who were given antineoplastic chemotherapy, give quite interesting information concerning the prevalence of $\mathrm{HBV}$ marker positivity among patients with solid tumours. This information becomes more important considering the fact that the Department of Medical Oncology gets the overwhelming majority of its referrals from the Medical and Surgical Outpatient Departments and the various Inpatient Departments of medical and surgical specialties of Evangelismos Hospital, the biggest general hospital in Greece with an inpatient turnover of 34000 a year. The findings that 443 out of 1008 patients (44\%) had at least one marker of HBV infection positive, provide an estimate of the cumulative incidence of previous exposure to $\mathrm{HBV}$ infection of the Greek cancer patients. An identical prevalence (43\%) was found among the 920 cancer patients, who received antineoplastic chemotherapy in our Unit.

Even more important, from the point of view of the possibility of developing reactivation of $\mathrm{HBV}$ infection, during chemotherapy, was our finding that 50 of these 920 patients $(5.4 \%)$ were $\mathrm{HBsAg}$ carriers. This prevalence is 9 times higher than that of Greek potential blood donors as it has been estimated in a recent multicentre Greek study comprising 542701 such persons, registered in the Blood Transfusion Units of the five biggest hospitals of Athens in the last 5 years (report in the 1st Hellenic Congress of Sexually Transmittable Diseases). Official data from the Greek Ministry of Health, concerning $70 \%$ of the Blood Transfusion Services in Greece, estimate the prevalence of HBsAg carrier state as $0.71 \%$. Nevertheless, this big difference in the prevalence of HbsAg positivity between cancer patients and potential blood donors must be interpreted with caution since blood donors are young and admittedly healthy people most of whom had apparently been self-selected for blood donation knowing their previous HBV profile. Unfortunately there exists no official information about the prevalence of HbsAg carrier state among the general Greek population.

Ohtsu et al (1991), observed a 3.4\% HBsAg carrier state among 262 patients with haematologic malignancies, a prevalence not significantly different from the $5.4 \%$ observed in our series although patient population in the two studies is not absolutely comparable. Patients in Ohtsu's study had exclusively haematological malignancies and the total number of patients tested was much smaller in his study.

Ngan et al (1995) reported a very high (30\%) HBsAg positivity among 73 consecutive Chinese patients with aggressive nonHodgkin's lymphomas treated between 1988 and 1995, a threefold increase compared with the incidence in general Chinese population. Again this is a very selected population of patients. Of interest are also our findings concerning the evolution of $\mathrm{HBV}$ profile after antineoplastic chemotherapy and during follow-up as there were observed in Group C and Group D of patients. While none of the HBs- and $\mathrm{HBe}$-negative patients of Group $\mathrm{C}$ developed $\mathrm{HBs}$ or $\mathrm{HBe}$ antigenaemia during chemotherapy, the overall change for HBsAb marker at the same period was $3.7 \%$, without any evidence of intervening $\mathrm{HBV}$ infection or biochemical signs of reactivation of a subclinical hepatitis. The corresponding overall change for $\mathrm{HBcAb}$ marker was $4.6 \%$. During the follow-up period (Group D), the biggest changes in the HBV profile were observed in $\mathrm{HBeAb}$ and $\mathrm{HBcAb}$ markers with overall changes of $16 \%$ and $13 \%$ respectively.

The evaluation of the behaviour of HBsAg carrier state and the systematic assessment of liver biochemistry, throughout chemotherapy, in the $50 \mathrm{HBsAg}$-positive patients, together with the findings of monitoring the complete $\mathrm{HBV}$ profile before, in the middle, just after completion of chemotherapy and repeatedly during the follow-up in $30(60 \%)$ of them, provide, we believe, valuable information on the possible consequences of antineoplastic chemotherapy and the likelihood of seroconversion in HBsAg carrier patients with solid tumours. An overall $14 \%$ of HBsAg carriers (seven patients), developed clinical picture and/or biochemical findings of hepatitis concurrently with the appearance, for the first time, of anti-HBs antibodies in the sera of six of them (persistently in three patients) and an associated decrease in their serum HBsAg levels (persistently in four patients). These findings together with the negative serological results for hepatitis $\mathrm{C}$ and $\mathrm{D}$, in all five cases tested, strongly support the explanation that the clinical and/or biochemical hepatitis observed in the seven $\mathrm{HbsAg}$ carriers is due to reactivation of $\mathrm{HBV}$ infection as a result of cytotoxic chemotherapy.

On the other hand, our finding that among the $30 \mathrm{HBsAg}$ carriers only $6.6 \%$ converted to a HBsAg-negative state, persisting during their follow-up, suggests that conversion of HBs antigenaemia as a result of antineoplastic chemotherapy, is neither a frequent nor usually a permanent phenomenon.

Wands et al (1975) reported an increase in serum titre of HBsAg after chemotherapy in all the HBsAg carriers among the 85 patients with haematological malignancies surveyed. Ohtsu et al (1991) observed that five of six HBsAg carriers with haematological malignancies who received chemotherapy containing prednisone, showed a rise in their serum titre of HBsAg. We believe that the difference between their observations and ours is mainly due to the fact that all their patients had haematological malignancies for which high doses of prednisone was given. Furthermore, their findings concern small numbers of patients retroprospectively studied. Our study, involving a significant number of patients followed up prospectively and serially throughout chemotherapy and during follow-up, offers, we think, a more realistic picture of the consequences of administration of antineoplastic chemotherapy in HBsAg carrier patients.

In conclusion, the prevalence of HBsAg carrier state in cancer patients is considerably high in Greece and very significantly higher than that of Greek blood donors. It seems that, during 
antineoplastic chemotherapy, one out of seven carriers will develop reactivation of $\mathrm{HBV}$ infection. It would, therefore, be advisable to screen all cancer patients for $\mathrm{HbsAg}$ prior to chemotherapy. Although the findings would probably not affect the decision about management, it seems prudent to closely follow those patients screened positive for the possibility of developing severe hepatitis.

Finally, disappearance of HBs antigenaemia following chemotherapy induced reactivation of $\mathrm{HBV}$ infection is an infrequent and usually transient phenomenon.

\section{REFERENCES}

Alexopoulos CG, Vaslamatzis M, Zoublios C and Chatzidimitriou G (1992) Reactivation of hepatitis B in HBsAg carriers during cancer chemotherapy. Ann Oncol 3: 65

Alexopoulos CG, Vaslamatzis M and Chatzidimitriou G (1997) Incidence of hepatitis B virus (HBV) positivity and behaviour of hepatitis B surface antigen (HBsAg) carrier state in cancer patients, during chemotherapy (CT). Proc Am Soc Clin Oncol 16: A1490

Bird GLA, Smith H, Portmann B, Alexander GJM and Williams R (1989) Acute liver decompensation on withdrawal of cytotoxic chemotherapy and immunosuppressive therapy in hepatitis B carriers. Quart J Med, New Series 73 270: 895-902

Gallbraith RM, Eddleston AL, Williams R, Zucherman AJ and Bagshaw KD (1975) Fulminant hepatic failure in leukemia and choriocarcinoma related to withdrawal of cytotoxic drug therapy. Lancet 2: 528-530
Hoofnagle JH, Dusheiko GM, Schafer DF, Jones EA, Micetich CK, Young CR and Costa J (1982) Reactivation of chronic hepatitis B virus infection by cancer chemotherapy. Am Intern Med 96: 447-449

Lau JYN, Lai CL, Lin HJ, Lok ASF, Liang RHS, Wu CP, Chan KT and Todd D (1989) Fatal reactivation of chronic hepatitis B virus infection following withdrawal of chemotherapy in lymphoma patients. Quart J Med New Series 73 270: 911-917

Nakamura Y, Motokura T, Fujita A, Yamashita T and Ogata E (1996) Severe hepatitis related to chemotherapy in hepatitis B virus carriers with hematologic malignancies. Survey in Japan 1987-1991. Cancer 78: 2210-2215

Ngan R, Tung S, Lau WH and Lam J (1995) Long term results of aggressive lymphoma using PROMACE-CYTABOM, peculiar patient group and toxicity. Proc Am Soc Clin Oncol 14: 1251

Ohtsu T, Sai T, Oka M, Shgai Y and Tobinai K (1991) Activation of hepatitis B virus infection by chemotherapy containing glucocorticoid in hepatitis B virus carriers with hematologic malignancies. Jpn J Clin Oncol 21: 360-365

Pinto CP, Hu E, Bernstein-Singer M, Pinter-Brown L and Govindarajans (1990) Acute hepatic injury after withdrawal of immunosuppressive chemotherapy in patients with hepatitis B. Cancer 65: 878-884

Scullard GH, Smith CI, Merigan TC, Robinson WS and Gregory PB (1981) Effects of immunosuppressive therapy on viral markers in chronic active hepatitis B. Gastroenterology 81: 987-991

Wands JR, Chura CM, Roll FJ and Maddrey WC (1975) Serial studies of hepatitisassociated antigen and antibody in patients receiving antitumor chemotherapy for myeloproliferative and lymphoproliferative disorders. Gastroenterology $\mathbf{6 8}$ $105-112$ 